\title{
Determination of the neutralization depth of concrete under the aggressive environment influence
}

\author{
Anastasia Morzhukhina ${ }^{1,}{ }^{*}$, Stanislav Nikitin ${ }^{1}$ and Elena Akimova \\ ${ }^{1}$ Peter the Great Saint-Petersburg Polytechnic University, 195251 St. Petersburg, Russia \\ ${ }^{2}$ Moscow State University of Civil Engineering, Yaroslavskoe shosse, 26, Moscow, 129337, Russia
}

\begin{abstract}
Aggressive environments have a significant impact on destruction of many reinforced concrete structures, such as high-rise constructions or chemical plants. For example, some high-rise constructions are equipped with a swimming pool, so they are exposed to chloride ions in the air. Penetration of aggressive chemical substances into the body of concrete contributes to acceleration of reinforced concrete structure corrosion that in turn leads to load bearing capacity loss and destruction of the building. The article considers and analyzes the main technologies for calculating penetration depth of various aggressive substances into the body of concrete. The calculation of corrosion depth was made for 50 -year service life.
\end{abstract}

\section{Introduction}

Exceptional durability of reinforced concrete structures is one of the main reasons for widespread use of this building material in the world.

However, material constraints, design and construction methods, as well as difficult service conditions, can lead to deterioration in quality of concrete and reinforcing bars corrosion that in turn can lead to aesthetic, functional or structural problems.

Reinforced concrete can be destroyed for various reasons, and specific damage is often the result of a combination of factors. One of the most common causes of reinforced concrete corrosion is aggressive environment penetration into the body of concrete, which subsequently causes reinforcing bars corrosion. Chemical aggression is the most violent and destructive.

Many buildings and structures are influenced by chemical attack, such as industrial buildings, tanks, chemical plants. High-rise constructions can also be affected by aggressive environments. For example, the high-rise building Velasca Tower in Milan has been exposed for a long period to carbon dioxide, which caused carbonation of concrete and corrosion of the reinforcement. Also, often in high-rise constructions design pools, in which rooms there is high moisture. In vapor and water there are chloride ions that penetrate concrete and cause chloride corrosion of the reinforced concrete structure [1-3].

\footnotetext{
* Corresponding author: a.morzhukhina@gmail.ru
} 


\section{Chloride corrosion}

The chloride ions effect on reinforced concrete structures is one of the main reasons for premature corrosion of steel reinforcement. Chloride ions, which present in crystals of salts and sea water, penetrate the thickness of reinforced concrete elements section and cause corrosion of reinforcing bars. Corrosion occurs only with high humidity and constant exposure to oxygen. Chlorides dissolved in water penetrate through cracks in concrete and reach the steel. The risk of corrosion increases as chloride content in the concrete increases. Corrosion process occurs, when chloride content on steel surface exceeds a certain limit [47].

\section{Sulfate corrosion}

Sulfate aggression is the most common aggression, since sulfate ions are present in almost all types of natural and waste water. In natural form, sodium, potassium, calcium or magnesium sulfates are sometimes found in soil or dissolved in groundwater. Sulfates can attack concrete by interacting with hydroxides in cement. These reactions can cause sufficient pressure to break cement by increasing its volume, which leads to a loss of strength characteristics. Sodium sulfate reacts with calcium hydroxide and water, forming calcium sulfate dihydrate $\mathrm{CaSO}_{4} \cdot 2 \mathrm{H}_{2} \mathrm{O}$ (gypsum).

Due to increase in volume of substances in the concrete, internal stresses appear. These stresses lead to cracks and destruction of its structure. It was also found that with decreasing temperature, concrete destruction under influence of sulfates is more significant [8-11].

\section{Material and methods}

From the experimental studies of concrete corrosion it is known that penetration of any aggressive substance into the concrete body is diffusive and causes a change in its physic and mechanical properties. Between the neutralized environment and healthy concrete, a boundary separating materials with different physical and mechanical properties can be drawn. This division is somewhat arbitrary. It is known that in a number of cases, depending on developing corrosion, the boundary between concrete layers that have been preserved in the damaged by corrosion can be traced with difficulty, and sometimes completely absent.

The results of various experimental works on reinforced concrete corrosion showed that when considering the influence of an aggressive environment on a reinforced concrete element, several factors must be considered. First, the depth of concrete neutralization is studied by an aggressive substance that penetrates into the concrete body, changes its physic and chemical properties and characterizes the protective properties of concrete in relation to the reinforcement. Secondly, consider the depth of concrete destruction, which determines reduction in the reinforced concrete element cross-section when concrete is destroyed by an aggressive substance. As shown by numerous laboratory and natural studies, the depth of concrete destruction is insignificant in comparison with the depth of neutralization for the same period [12].

The most objective quantitative characteristic of concrete corrosive process will be considered the depth of concrete neutralization by aggressive substance for a certain period of time. The rate of concrete neutralization depends on many factors, such as:

- type of aggressive environment;

- concentration of corrosive substances in contact with concrete surface;

- composition of concrete;

- observed relative humidity.

An indicator that estimates the penetration depth is proposed to be determined by a formula that looks like: 


$$
\delta=k(\xi) \cdot \sqrt{D^{*} \cdot \tau}
$$

Here $\mathrm{k}(\xi)$ - coefficient; $\tau$ - time of exposure of aggressive substance to concrete; $\mathrm{D}^{*}$ - effective diffusion coefficient of corrosive substance through the layer of corrosion products determined experimentally $\left(\right.$ at $\mathrm{t}=20^{\circ} \mathrm{C}$ ) and presented in Table 1 .

For practical calculations of the corrosion depth at temperatures other than $20^{\circ} \mathrm{C}$, the $\mathrm{D}$ * value can be calculated taking into account that an increase or decrease in temperature by $1^{\circ} \mathrm{C}$ gives an increase or decrease of $\mathrm{D}^{*}$ by $2.6 \%$, respectively.

Table 1 The value of effective diffusion coefficient.

\begin{tabular}{|l|l|l|l|}
\hline Type of acid & Concentration, $\mathrm{H}$ & $\mathrm{pH}$ value & $\mathrm{D}^{*}, \mathrm{sm}^{2} / \mathrm{h}$ \\
\hline $\mathrm{HCl}$ & $0,0001-0,1$ & $4-1,5$ & 0,047 \\
\hline $\mathrm{H}_{2} \mathrm{SO}_{4}$ & $0,0001-0,035$ & $4-1,5$ & 0,041 \\
\hline
\end{tabular}

It has been suggested that $\mathrm{k}(\xi)$ be determined by a formula that takes into account the influence of the water-cement ratio on the chemical process [13]:

$$
k(\xi)=A \cdot \sqrt{C \cdot E}
$$

Here $\mathrm{E}$ - chemical equivalent of ratio of calcium oxide molar mass $\mathrm{M}_{1}$ and aggressive substance molar mass $\mathrm{M}_{2} . \mathrm{E}=\mathrm{mM}_{1} / \mathrm{nM}_{2}$ (m, $\mathrm{n}$ - stoichiometric coefficients of reaction equation between acid and calcium oxide, $\mathrm{C}$ - concentration of aggressive substance, $\mathrm{A}$ - coefficient that depends on composition of concrete and is equal:

$$
A=\sqrt{\frac{2\left(\frac{1}{\rho_{c}}+\frac{W / C}{\rho_{w}}\right)}{K^{*}}}
$$

where $\rho_{c}$ and $\rho_{w}$ - true density of cement and water, respectively; $K^{*}-$ mass content of calcium oxide in cement, $\mathrm{W} / \mathrm{C}$ - water-cement ratio.

The Russian researcher Popesko proposed a modification of formula (1).

All studies on the kinetics of corrosion of concrete confirm that the depth of its neutralization is correlated with the time of action of corrosive substance. [14-15] Therefore, in the first approximation, for a mathematical description of given dependence, we can take the model in the form of a power function. Based on the results of research and experimental materials, Popesko proposed the depth concrete corrosion to be determined by a formula of the form:

$$
\delta=K \cdot t^{0,5}
$$

where $\mathrm{K}$ - coefficient of aggressiveness of a particular substance to a certain class of concrete, determined experimentally; $\mathrm{t}$ - time of action of aggressive environment.

\section{Results}

The depth of neutralization of concrete depends on type of corrosive effect. We consider the effect of $1 \%$ solutions of sulfuric and hydrochloric acids. For concrete of class B25 of reduced permeability (W6) the value of coefficient A was calculated, it's equal to $5.25 \cdot 10^{-2}$. The molar masses of substances are: $M_{\mathrm{CaO}}=56,08 \mathrm{~g} /$ mole $, M_{\mathrm{HCl}}=36,46 \mathrm{~g} /$ mole $, M_{\mathrm{H}_{2} \mathrm{SO}_{4}}=98,08 \mathrm{~g} / \mathrm{mole}$ 
The value of coefficient $\mathrm{K}$ for a $1 \%$ solution of hydrochloric and sulfuric acids is, respectively, 0.11 and 0.029 .

The calculated values of corrosive destruction depth of low-permeability concrete (W6) under the action of $1 \% \mathrm{HCl}$ and $\mathrm{H}_{2} \mathrm{SO}_{4}$ solutions on them are given in Table 2.

Table 2 Values of concrete neutralization depth for 50 years.

\begin{tabular}{|c|c|c|c|c|c|}
\hline \multirow{2}{*}{$\begin{array}{c}\text { Item } \\
\text { No. }\end{array}$} & \multirow{2}{*}{$\begin{array}{c}\text { Service life, } \\
\text { years }\end{array}$} & \multicolumn{4}{|c|}{ Concrete neutralization depth, mm } \\
\cline { 3 - 6 } & & \multicolumn{2}{|c|}{ By the formula 1} & \multicolumn{2}{c|}{ By the formula 2} \\
\cline { 3 - 6 } & $1 \%$ sol. $\mathrm{H}_{2} \mathrm{SO}_{4}$ & $1 \%$ sol. $\mathrm{HCl}$ & $1 \%$ sol. $\mathrm{H}_{2} \mathrm{SO}_{4}$ & $1 \%$ sol. $\mathrm{HCl}$ \\
\hline 1 & 1 & 2.38 & 5.68 & 1.00 & 3.81 \\
\hline 2 & 3 & 4.12 & 9.83 & 1.74 & 6.60 \\
\hline 3 & 5 & 5.32 & 12.70 & 2.25 & 8.52 \\
\hline 4 & 10 & 7.52 & 17.95 & 3.18 & 12.05 \\
\hline 5 & 15 & 9.21 & 21.99 & 3.89 & 14.76 \\
\hline 6 & 25 & 11.89 & 28.39 & 5.02 & 19.05 \\
\hline 7 & 50 & 16.81 & 40.15 & 7.10 & 26.94 \\
\hline
\end{tabular}

\section{Conclusion}

In the course of this research, concrete neutralization depth was determined under influence of sulfuric and hydrochloric acid solutions on concrete for 50 years of working. When comparing the results, we see that chloride corrosion has more negative effect than sulfate corrosion under equal conditions for the same period of exposure time. Comparative analysis of two methods for calculating the depth of concrete corrosion revealed that the results are significantly different.

The expediency and effectiveness of the application of protective measures should be assessed by comparing the values of unprotected concrete corrosive destruction depth with the allowable depth of failure during the overhaul period, provided that the load bearing capacity of the structure is maintained.

If during the design service life due to corrosive effect of corrosive environment on the structure, surface layer of concrete is destroyed and the reduction in the cross-sectional area doesn't cause an increase in stresses above the maximum permissible value and there is no risk of reinforcement corrosion, then protection can be discarded.

The protective properties of concrete in a slightly aggressive acid environment can be increased by use of primary protection - by increasing the concrete density, the protective layer thickness and the structures size.

\section{References}

1. F. Lollini, E. Redaelli, L. Bertolini, CSCM 4, 55-61 (2016)

2. M. Torres-Luquea, E. Bastidas-Arteagab, F. Schoefsb, S.-M. Sánchez, J.F. Osma, CBM 68, 68-81 (2014)

3. N.N. Skoblinskaja, K.G. Krasilnikov, L.V. Nikitina, Varlamov, CCR 5, (1975)

4. A. Boddy, E. Bentz, M. D. A. Thomas, and R. D. Hooton, CCR 29, 827-837 (1999)

5. X. Shia, N. Xiec, K. Fortunea, J. Gong, CBM 30, 125-138 (2012)

6. V.V. Belov, S.E Nikitin, IOPE 4, 142-147 (2013) 
7. V.P. Selyaev, V.A. Neverov, P.V. Selyaev, E.V. Sorokin, O.A. Yudina, MCE 1, 41-52 (2014)

8. P. N. Gospodinov, R. F. Kazandjiev, M. Mironova, CCC 18, 401-407 (1996)

9. V. Zivica, A. Bajza, CBM 15, 331-340 (2000)

10. P. K. Mehta, CI, 57-61 (2000)

11. J. B. Aguiar, A. Camoes, P.M. Moreira, IJCSM 2, 21-25 (2008)

12. H. Nagano, T. Otani, Y. Sato, Y. Akiyoshi, H. Matsui, T. Mishima, PTE LTD 35, 1-9 (2010)

13. S. Sato, Y Masuma, Y. Hasegawa, I. Natsuka, A. Aoyama, K. Yokoi, OWCS, 373-380 (2011)

14. A. Pustovgar, A. Adamtsevich, L. Shilova, Advances in Intelligent Systems and Computing, 692, pp. 608 - 614 (2018) DOI - 10.1007/978-3-319-70987-1_64

15. A.O. Adamtsevich, A.P. Pustovgar, S.A. Pashkevich, A.V. Eremin, Calorimetric methods in analysis of composite building materials, International Journal of Applied Engineering Research, 11, pp. 1609 - 1611 (2016) 